\title{
PROGNOSTIC MODELS OF THIRTY-DAY MORTALITY AND MORBIDITY AFTER MAJOR PULMONARY RESECTION
}

David H. Harpole, Jr, MD

Malcolm M. DeCamp, Jr, MD

Jennifer Daley, MD

Kwan Hur, MS

Charles A. Oprian, $\mathrm{PhD}$

William G. Henderson, $\mathrm{PhD}$

Shukri F. Khuri, MD

Participants in the National Veterans Affairs Surgical Quality Improvement

Program
Background: A part of the prospective, multi-institutional National Veterans Affairs Surgical Quality Improvement Program was developed to predict 30-day mortality and morbidity for patients undergoing a major pulmonary resection. Methods: Perioperative data were acquired from 194,319 noncardiac surgical operations at 123 Veterans Affairs Medical Centers between October 1, 1991, and August 31, 1995. Current Procedural Terminology code-based analysis was undertaken for major pulmonary resections (lobectomy and pneumonectomy). Preoperative, intraoperative, and outcome variables were collected. The 30-day mortality and morbidity models were developed by means of multivariable stepwise logistic regression with the preoperative and intraoperative variables used as independent predictors of outcome. Results: A total of 3516 patients (mean age $64 \pm 9$ years) underwent either lobectomy $(n=$ 2949) or pneumonectomy $(n=567)$. Thirty-day mortality was $4.0 \%$ for lobectomy (119/2949) and $11.5 \%$ for pneumonectomy $(65 / 567)$. The preoperative predictors of 30-day mortality were albumin, do not resuscitate status, transfusion of more than 4 units, age, disseminated cancer, impaired sensorium, prothrombin time more than 12 seconds, type of operation, and dyspnea. When the intraoperative variables were considered, intraoperative blood loss was added to the preoperative model. In the presence of these intraoperative variables in the model, do not resuscitate status and prothrombin time more than 12 seconds were only marginally significant. Thirty-day morbidity, defined as the presence of 1 or more of the 21 predefined complications, was $23.8 \%$ for lobectomy (703/2949) and $25.7 \%$ for pneumonectomy (146/567). In multivariable models, independent preoperative predictors $(P<.05)$ of 30-day morbidity were age, weight loss greater than $10 \%$ in the 6 months before surgery, history of chronic obstructive pulmonary disease, transfusion of more than 4 units, albumin, hemiplegia, smoking, and dyspnea. When intraoperative variables were added to the preoperative model, the duration of operation time and intraoperative transfusions were included in the model and albumin became marginally significant. Conclusions: This analysis identifies independent patient risk factors that are associated with 30-day mortality and morbidity for patients undergoing a major pulmonary resection. This series provides an initial risk-adjustment model for major pulmonary resections. Future refinements will allow comparative assessment of surgical outcomes and quality of care at many institutions. (J Thorac Cardiovasc Surg 1999;117:969-79)
From the Veterans Affairs Medical Center/Harvard Medical School, Brockton/West Roxbury, Mass; the Veterans Affairs Medical Center/Duke University Medical Center, Durham, NC; and the Cooperative Studies Program Coordinating Center, Veterans Affairs Medical Center, Hines, Ill.

Presented in part at the Thirtieth Annual Session of The Society of Thoracic Surgeons, Palm Springs, Calif, 1995.

Supported by the Department of Veterans Affairs Office of Patient Care Services, the Health Services Research and Development Service, and the Cooperative Studies Program. Jennifer Daley, MD, is a Senior Research Associate in the Career Development
Award Program of the Health Services Research and Development of the Department of Veterans Affairs.

Received for publication May 27, 1998; revisions requested Sept 10, 1998; revisions received Dec 10, 1998; accepted for publication Jan 12, 1999.

Address for reprints: David H. Harpole, Jr, MD, Chief, Cardiothoracic Surgery, Durham VA Medical Center, 10 Fulton St, Durham, NC 27705.

12/1/97049 
Several single-institution, retrospective series have been published that examine patient characteristics associated with an increased risk of mortality and morbidity after major pulmonary resection. Because series span several decades and are of limited size, multivariable analyses were not undertaken. ${ }^{1-12}$ The National Veterans Affairs (VA) Surgical Quality Improvement Program was designed to prospectively collect historical, laboratory, operative, and postoperative patient characteristics and clinical outcomes for many operative procedures from several surgical subspecialties. The goal of the study was to develop tools for future risk-adjusted models of mortality and morbidity that would allow for the comparative assessment of the quality of surgical care at various institutions. ${ }^{13-18}$ This project examined the subset of patients who had undergone a major pulmonary resection (lobectomy or pneumonectomy).

\section{Methods}

The methods of the National VA Surgical Quality Improvement Program have been described in detail elsewhere. ${ }^{13}$

Population. Data were acquired prospectively on 194,319 consecutive patients undergoing noncardiac surgical procedures from October 1, 1991, until August 31, 1995, in 123 Department of VA Medical Centers. The database included 10,008 patients who had undergone a lung operation, of which 3516 (35\%) were for a major pulmonary resection (Current Procedural Terminology [CPT] codes 32440-32445 and 32480-32488). International Classification of Diseasesninth revision-Clinical Modification (ICD-9-CM) diagnoses for these pulmonary resections included 3251 for cancer (non-small cell lung cancer $=3105$, pulmonary metastatic cancer $=146$ ), 34 benign lung masses (hamartoma or typical carcinoid), 156 infectious processes (Mycobacterium tuberculosis $=27$, fungal $=36$, bronchiectasis $=25$, infectious massive hemoptysis $=19$, inflammatory lung masses with pneumonia $=49$ ), and 51 other lung masses (not otherwise stated).

Patient characteristics and clinical outcomes. A total of 122 separate variables were recorded for each operation by a dedicated surgical nurse reviewer who was independent of the various surgical teams, allowing unbiased data collection. Each reviewer was educated on the set of standard criteria for coding all collected variables. These variables were selected by a committee of expert advisors to the VA National Surgical Quality Improvement Program, and the data management manual was made available on the Internet in late 1998. A system of data audits was performed throughout the study interval to ensure data quality and completeness. In brief, after the data manager education process was completed, each center underwent periodic internal and external random audits for data quality. Whenever possible, data were directly downloaded to the statistical center from each VA Medical Center's computer (ie, laboratory results). A more complete description of the data collection and auditing process is given in a manuscript presented at the 1998 meeting of the American Surgical Association. ${ }^{14}$

Preoperative patient characteristics included 4 demographic, 43 historical (divided among anatomic systems), and 17 preoperative laboratory values. Thirteen intraoperative and operation-specific variables were recorded. Follow-up 30-day postoperative mortality statistics and the presence of any one of 21 pre-defined postoperative complications occurring within 30 days of the index operation were recorded (Appendix 1).

Statistical analysis. Univariate analyses were performed on the preoperative, demographic, and laboratory variables, relating them to operative mortality and morbidity. In the case of continuous variables, an unpaired $t$ test was used. For the categoric variables, a $\chi^{2}$ test was used. The variables with a prevalence of greater than $0.5 \%$ that were univariately significant at $P<.20$ were considered as possible independent variables in a multivariable logistic regression. Stepwise logistic regression analysis with entry and exit criteria set at the $P=$ .05 level was used with 30-day mortality as the dependent variable. For morbidity, the presence or absence of one or more complications was used as the dependent variable.

Subsequent mortality and morbidity models were developed to incorporate the type of operation (pneumonectomy or lobectomy) and then the intraoperative variables such as operation time and amount of blood loss. The modeling was done in a 2-stage process. The first-stage model consisted of preoperative variables and the type of operation. In the second stage the variables from the preoperative model were fixed and the intraoperative variables were added to these for possible inclusion in the stage 2 model. The second-stage model then consists of the first-stage model plus the intraoperative variables that were significant in the second model. Variables in the models are listed in Appendix 2.

All data were more than $99 \%$ complete, including the preoperative laboratory variables, except for serum albumin (78\%), serum bilirubin (79\%), alkaline phosphatase (77\%), and serum aspartate aminotransferase $(75 \%)$. A regression procedure was used to impute missing laboratory values. ${ }^{19,20}$ Some of the laboratory variables were not linearly related to the postoperative outcomes, but rather had U shapes or inverted J shapes. In these cases, the categorized laboratory variables based on clinical cutoff points were entered into the models.

To investigate the stability of the models, we used a bootstrap technique. ${ }^{21,22}$ In the bootstrap procedure, repeated samples of $\mathrm{n}$ observations are selected with replacement from the original set of $n$ observations. For each sample, forward stepwise logistic regression was performed simultaneously entering the preoperative and intraoperative variables listed in Appendix 1. The stability of the final stepwise model can be assessed by identifying the variables that enter most frequently in the repeated bootstrap models and comparing those variables with the variables in the final stepwise model. If the final stepwise model variables occur in a majority $(>50 \%)$ of the bootstrap models, the original final stepwise regression model can be judged to be stable. 
Table I. Frequency distribution of selected patient characteristics and preoperative risk factors among 3516 patients undergoing lobectomy and pneumonectomy

\begin{tabular}{lrr}
\hline Variable & No. & $\%$ \\
\hline Male sex & 3471 & 98.7 \\
Smoking during the 2 weeks before & 1806 & 51.4 \\
$\quad$ admission & & \\
Chronic obstructive pulmonary disease & 1372 & 39.0 \\
Hypertension requiring medication & 1319 & 37.5 \\
Moderate or severe dyspnea & 1163 & 33.1 \\
More than two alcoholic drinks per day & 657 & 18.7 \\
$\quad$ during the 2 weeks before admission & & \\
Diabetes mellitus requiring insulin & 395 & 11.2 \\
$\quad$ or oral agents & & \\
Weight loss > 10\% in 6 months before & 383 & 10.9 \\
$\quad$ surgery & & \\
Previous PTCA or coronary bypass & 365 & 9.6 \\
Previous stroke or transient ischemic & 338 & 5.6 \\
$\quad$ attack & & 4.0 \\
Below- or above-knee amputation & 198 & 2.3 \\
Long-term steroid use & 139 & 2.3 \\
Congestive heart failure & 81 & 1.1 \\
Drug addiction & 80 & 39 \\
Hemiplegia & & \\
\hline
\end{tabular}

\section{Results}

Patient characteristics and outcomes. The population for this project consisted of 3516 patients who underwent either an anatomic lobectomy $(n=2949)$ or a pneumonectomy $(n=567)$. The mean age for the study sample is 64 years with a standard deviation of 9 years and a range from 22 to 91 years. The majority of the population was male $(98.7 \%)$. Other selected patient characteristics are listed in Table I. There were 119 deaths within 30 days for the patients undergoing lobectomy (4.0\%) and 65 deaths for those undergoing pneumonectomy (11.5\%), for an overall 30-day mortality of $5.2 \%$ in the 3516 patients. The postoperative morbidity for the lobectomy patients was $23.8 \%$ (703/2949) and for the pneumonectomy patients was $25.7 \%$ (146/567). The overall 30-day morbidity was $24.1 \%$ (849/3516). The most frequently occurring complications were pneumonia $(11.7 \%$ for lobectomy and $9.7 \%$ for pneumonectomy) followed by unplanned reintubation $(7.9 \%$ and $10.6 \%)$. Other individual complication rates are shown in Table II.

Univariate analyses. Patient characteristics associated with an increased risk of 30-day mortality $(P<.2)$ included 24 preoperative clinical, 9 laboratory, and 4 intraoperative variables. Patient characteristics associated with an increased risk of 30-day morbidity included 24 preoperative, 9 laboratory, and 3 intraoperative variables. Eighteen preoperative and 6 laboratory vari-
Table II. Observed 30-day mortality and morbidity by primary operative procedure

\begin{tabular}{|c|c|c|c|c|}
\hline \multirow[b]{2}{*}{ Variable } & \multicolumn{2}{|c|}{$\begin{array}{l}\text { Lobectomy } \\
(n=2949)\end{array}$} & \multicolumn{2}{|c|}{$\begin{array}{c}\text { Pneumonectomy } \\
(n=567)\end{array}$} \\
\hline & No. & $\%$ & No. & $\%$ \\
\hline Thirty-day mortality & 119 & 4.0 & 65 & 11.5 \\
\hline $\begin{array}{l}\text { Thirty-day morbidity } \\
\text { ( } 1 \text { or more complications) }\end{array}$ & 703 & 23.8 & 146 & 25.7 \\
\hline \multicolumn{5}{|l|}{ Respiratory complications } \\
\hline Pneumonia & 344 & 11.7 & 55 & 9.7 \\
\hline Unplanned reintubation & 234 & 7.9 & 60 & 10.6 \\
\hline Failure to wean more than $48 \mathrm{~h}$ & 194 & 6.6 & 53 & 9.3 \\
\hline Pulmonary embolism & 20 & 0.7 & 8 & 1.4 \\
\hline \multicolumn{5}{|l|}{ Cardiac complications } \\
\hline Pulmonary edema & 91 & 3.1 & 39 & 6.9 \\
\hline Cardiac arrest with CPR & 76 & 2.6 & 39 & 6.9 \\
\hline Myocardial infarction & 24 & 0.8 & 5 & 0.9 \\
\hline \multicolumn{5}{|l|}{ Wound complications } \\
\hline Superficial wound infection & 41 & 1.4 & 9 & 1.6 \\
\hline Deep wound infection & 35 & 1.2 & 6 & 1.1 \\
\hline Wound dehiscence & 8 & 0.3 & 5 & 0.9 \\
\hline \multicolumn{5}{|l|}{ CNS complications } \\
\hline Coma more than $24 \mathrm{~h}$ & 19 & 0.6 & 6 & 1.1 \\
\hline Stroke with neurologic deficit & 17 & 0.6 & 6 & 1.1 \\
\hline Cerebral vascular accident & 14 & 0.5 & 5 & 0.9 \\
\hline \multicolumn{5}{|l|}{ Urinary tract complications } \\
\hline Urinary tract infection & 77 & 2.6 & 9 & 1.6 \\
\hline Progressive renal insufficiency & 31 & 1.0 & 10 & 1.8 \\
\hline Acute renal failure & 20 & 0.7 & 8 & 1.4 \\
\hline \multicolumn{5}{|l|}{ Other complications } \\
\hline $\begin{array}{l}\text { Bleeding requiring }>4 \text { units } \\
\text { transfusion }\end{array}$ & 85 & 2.9 & 17 & 3.0 \\
\hline Systemic sepsis & 80 & 2.7 & 16 & 2.8 \\
\hline Ileus/bowel obstruction & 49 & 1.7 & 6 & 1.1 \\
\hline Deep venous thrombosis & 20 & 0.7 & 4 & 0.7 \\
\hline Graft/prosthesis failure & 1 & 0.0 & 2 & 0.4 \\
\hline
\end{tabular}

$C P R$, Cardiopulmonary resuscitation; $C N S$, central nervous system.

ables were commonly significant in the univariate analyses for both mortality and morbidity.

Multivariable analyses. All factors with a prevalence of greater than $0.5 \%$ of the sample and a univariate significance of $P<.2$ were placed into a multivariable stepwise logistic regression analysis to identify risk factors associated with mortality and morbidity. In the multivariable logistic regression model for mortality, the preoperative independent predictors $(P<.05)$ were serum albumin, do not resuscitate status before the operation, transfusion of more than 4 units of red blood cells before the operation, age, disseminated cancer (defined as a resection for a pulmonary metastasis or for patients with clinical evidence of mediastinal lymph nodes in non-small cell lung cancer), impaired sensorium, prothrombin time of more than 12 seconds, operation type, and dyspnea. The $\beta$ coefficients for 
Table III-a. Multivariable logistic regression model of 30-day mortality (preoperative variables and type of operation)

\begin{tabular}{|c|c|c|c|c|}
\hline Variable & $\beta$ Coefficient & $S E$ & $\mathrm{P}$ value & $O R$ \\
\hline Intercept & -2.1970 & 0.8726 & & \\
\hline $\begin{array}{l}\text { Higher serum albumin } \\
(\mathrm{g} / \mathrm{dL})\end{array}$ & -.6449 & 0.1537 & .0001 & 0.525 \\
\hline $\begin{array}{l}\text { Do not resuscitate status } \\
\text { present }\end{array}$ & 1.4606 & 0.4855 & .0026 & 4.309 \\
\hline $\begin{array}{l}\text { Preoperative transfusion } \\
>4 \mathrm{RBC} \text { units present }\end{array}$ & 1.9398 & 0.5685 & .0006 & 6.957 \\
\hline Older age (y) & .0327 & 0.0099 & .0010 & 1.033 \\
\hline $\begin{array}{l}\text { Disseminated cancer } \\
\text { present }\end{array}$ & .6959 & 0.2572 & .0068 & 2.006 \\
\hline $\begin{array}{l}\text { Impaired sensorium } \\
\text { present }\end{array}$ & .9974 & 0.4050 & .0138 & 2.711 \\
\hline $\begin{array}{l}\text { Prothrombin time } \\
>12 \text { s present }\end{array}$ & .3627 & 0.1593 & .0228 & 1.437 \\
\hline Dyspnea present & .3359 & 0.1586 & .0342 & 1.399 \\
\hline $\begin{array}{l}\text { Pneumonectomy } \\
\text { operations (vs lobectom }\end{array}$ & $\begin{array}{l}-1.1103 \\
\text { ny) }\end{array}$ & 0.1700 & .0001 & 3.035 \\
\hline \multicolumn{5}{|c|}{-2 LOG likelihood = 1317.1} \\
\hline \multicolumn{5}{|l|}{ C-index $=0.729$} \\
\hline \multicolumn{5}{|c|}{ Hosmer-Lemeshow statistic $=4.74(P=.7851)$} \\
\hline
\end{tabular}

The present/absent dichotomous risk variables were all coded as $0=$ absent, $1=$ present in the logistic regression analysis. Type of operation was coded as $0=$ lobectomy, 1 = pneumonectomy. $S E$, Standard error; $O R$, odds ratio; $R B C$, red blood cell.

these variables along with their $P$ values and associated odds ratios are contained in Table III-a. When the intraoperative variables are added for possible entry into this logistic model for mortality, the combined model contains the preoperative predictors and the intraoperative blood loss. This combined model is described in Table III-b.

In the multivariable morbidity model, the preoperative predictors significant at the .05 level were age, weight loss of more than $10 \%$, history of chronic obstructive pulmonary disease, transfusion of more than 4 units of red blood cells, serum albumin, hemiplegia, smoking, and dyspnea. Table IV-a contains the $\beta$ coefficients, $P$ values, and odds ratios for this model. When the intraoperative variables are added, the resultant combined model includes the preoperative predictors with operation time and intraoperative red blood cell units transfused. Table IV-b lists the result of this model.

Model validation. The predictive validity (discrimination) of the model was measured by means of the cindex. $^{23,24}$ The c-indexes for the mortality models were 0.729 for the preoperative model and 0.749 for the model including the intraoperative variables. The cindexes for the respective morbidity models were 0.623 and 0.646. These indexes indicate a moderate level of predictability. The model fit was measured with the
Table III-b. Multivariable logistic regression model of 30-day mortality (preoperative variables, type of operation, and intraoperative variables)

\begin{tabular}{|c|c|c|c|c|}
\hline Variable & $\beta$ Coefficient & $S E$ & $\mathrm{P}$ value & OR \\
\hline Intercept & -3.2584 & 0.9073 & & \\
\hline $\begin{array}{l}\text { Higher serum albumin } \\
(\mathrm{g} / \mathrm{dL})\end{array}$ & -.5075 & 0.1592 & .0014 & 0.602 \\
\hline $\begin{array}{l}\text { Do not resuscitate status } \\
\text { present }\end{array}$ & 1.0205 & 0.5592 & .0680 & 2.775 \\
\hline $\begin{array}{l}\text { Preoperative transfusion } \\
>4 \mathrm{RBC} \text { units present }\end{array}$ & 1.9731 & 0.5704 & .0005 & 7.193 \\
\hline Older age (y) & .0356 & 0.0100 & .0004 & 1.036 \\
\hline $\begin{array}{l}\text { Disseminated cancer } \\
\text { present }\end{array}$ & .6848 & 0.2588 & .0081 & 1.983 \\
\hline $\begin{array}{l}\text { Impaired sensorium } \\
\text { present }\end{array}$ & .9749 & 0.0452 & .0161 & 2.651 \\
\hline $\begin{array}{l}\text { Prothrombin time } \\
>12 \text { s present }\end{array}$ & 3007 & 0.1619 & .0633 & 1.351 \\
\hline Dyspnea present & .3176 & 0.1610 & .0485 & 1.374 \\
\hline $\begin{array}{l}\text { Pneumonectomy } \\
\text { (vs lobectomy) }\end{array}$ & -.9978 & 0.1737 & .0001 & 2.712 \\
\hline $\begin{array}{l}\text { Intraoperative blood loss } \\
(\mathrm{mL})\end{array}$ & .0006 & 0.0001 & .0001 & 1.001 \\
\hline \multicolumn{5}{|l|}{-2 LOG likelihood $=1286.3$} \\
\hline \multicolumn{5}{|l|}{ C-index $=0.749$} \\
\hline \multicolumn{5}{|c|}{ Hosmer-Lemeshow statistic $=6.56(P=.5845)$} \\
\hline
\end{tabular}

The present/absent dichotomous risk variables were all coded as $0=$ absent, $1=$ present in the logistic regression analysis. Type of operation was coded as $0=$ lobectomy, 1 = pneumonectomy. $S E$, Standard error; $O R$, odds ratio; $R B C$, red blood cell.

Hosmer-Lemeshow ${ }^{25}$ statistic. The Hosmer-Lemeshow statistics for the mortality models were $4.74(P=.79)$ and $6.56(P=.58)$. The corresponding HosmerLemeshow statistics for the morbidity models were 5.81 $(P=.67)$ and $8.43(P=.39)$. These Hosmer-Lemeshow statistics show a good level of fit for each of the models.

In addition, the stability of the mortality and morbidity models was verified with a bootstrap resampling method. ${ }^{26,27}$ The bootstrap resampling technique was performed on 200 random samples for both mortality and morbidity with the use of the preoperative and intraoperative variables that were univariately significant. All the variables in the final mortality model were included in a majority of the 200 bootstrap replications except for dyspnea and prothrombin time. For morbidity, all variables in the final model were included in at least $50 \%$ of the bootstrap replications, except for smoking and albumin (Table V).

\section{Discussion}

Purpose of study. Advances in surgery require prospectively collected, accurate, and reliable outcome data. The Department of VA Medical Centers is an excellent place to create an outcome database, because 
Table IV-a. Multivariable logistic regression model of 30-day morbidity (preoperative variables and type of operation)

\begin{tabular}{|c|c|c|c|c|}
\hline Variable & $\beta$ coefficient & $S E$ & P value & OR \\
\hline Intercept & -2.3979 & 0.4981 & & \\
\hline Older age (y) & .0291 & 0.0050 & .0001 & 1.030 \\
\hline $\begin{array}{l}\text { Weight loss > 10\% } \\
\text { present }\end{array}$ & .4762 & 0.1209 & .0001 & 1.610 \\
\hline $\begin{array}{l}\text { History of COPD } \\
\text { present }\end{array}$ & .2830 & 0.0847 & .0008 & 1.327 \\
\hline $\begin{array}{l}\text { Preoperative transfusion } \\
>4 \mathrm{RBC} \text { units present }\end{array}$ & 1.7901 & 0.5254 & .0007 & 5.990 \\
\hline $\begin{array}{l}\text { Higher serum albumin } \\
(\mathrm{g} / \mathrm{dL})\end{array}$ & -0.2710 & 0.0896 & .0025 & 0.763 \\
\hline Hemiplegia present & .9233 & 0.3307 & .0052 & 2.518 \\
\hline Smoking present & .2114 & 0.0831 & .0109 & 1.235 \\
\hline Dyspnea present & .2386 & 0.0866 & .0059 & 1.269 \\
\hline \multicolumn{5}{|c|}{-2 LOG likelihood $=3754.5$} \\
\hline \multicolumn{5}{|c|}{ C-index $=0.623$} \\
\hline \multicolumn{5}{|c|}{ Hosmer-Lemeshow statistic $=5.81(P=.6684)$} \\
\hline
\end{tabular}

The present/absent dichotomous risk variables were all coded as $0=$ absent, $1=$ present in the logistic regression analysis. $S E$, Standard error; $O R$, odds ratio; $C O P D$, chronic obstructive pulmonary disease; $R B C$, red blood cell.
Table IV-b. Multivariable logistic regression model of 30-day morbidity (preoperative variables, type of operation, and intraoperative variables)

\begin{tabular}{|c|c|c|c|c|}
\hline Variable & $\beta$ coefficient & $S E$ & $\mathrm{P}$ value & $O R$ \\
\hline Intercept & -3.4339 & 0.5253 & & \\
\hline Older age (y) & .0314 & 0.0051 & .0001 & 1.032 \\
\hline $\begin{array}{l}\text { Weight loss }>10 \% \\
\text { present }\end{array}$ & .4719 & 0.1223 & .0001 & 1.603 \\
\hline History of COPD present & .2621 & 0.0855 & .0022 & 1.300 \\
\hline $\begin{array}{l}\text { Preoperative transfusion } \\
>4 \mathrm{RBC} \text { units present }\end{array}$ & 1.6634 & 0.5355 & .0019 & 5.277 \\
\hline $\begin{array}{l}\text { Higher serum albumin } \\
(\mathrm{g} / \mathrm{dL})\end{array}$ & -0.1501 & 0.0929 & .1062 & 0.861 \\
\hline Hemiplegia present & .9708 & 0.3326 & .0035 & 2.640 \\
\hline Smoking present & .2363 & 0.0840 & .0049 & 1.267 \\
\hline Dyspnea present & .2435 & 0.0875 & .0054 & 1.276 \\
\hline Longer operation time (h) & .1013 & 0.0270 & .0002 & 1.107 \\
\hline $\begin{array}{l}\text { Intraoperative RBC unit } \\
\text { transfusion }\end{array}$ & .2309 & 0.0449 & .0001 & 1.260 \\
\hline \multicolumn{5}{|l|}{-2 LOG likelihood $=3698.3$} \\
\hline \multicolumn{5}{|l|}{ C-index $=0.646$} \\
\hline \multicolumn{5}{|c|}{ Hosmer-Lemeshow statistic $=8.43(P=.3929)$} \\
\hline
\end{tabular}

The present/absent dichotomous risk variables were all coded as $0=$ absent, $1=$ present in the logistic regression analysis. $S E$, Standard error; $O R$, odds ratio; $C O P D$, chronic obstructive pulmonary disease; $R B C$, red blood cell.

Table V. Morbidity and mortality bootstrap results

\begin{tabular}{|c|c|c|c|c|c|}
\hline \multicolumn{3}{|c|}{ Mortality bootstrap } & \multicolumn{3}{|c|}{ Morbidity bootstrap } \\
\hline Variable & requency selected & $\%$ & Variable & Frequency selected & $\%$ \\
\hline Age & 200 & 100 & Type of operation & 200 & 100 \\
\hline Operation time & 195 & 97.5 & Age & 185 & 92.5 \\
\hline Weight loss $>10 \%$ & 190 & 95.0 & Intraoperative blood loss & 142 & 71.0 \\
\hline Intraoperative $\mathrm{RBC}$ unit transfusion & 170 & 85.0 & Disseminated cancer & 134 & 67.0 \\
\hline History of COPD & 164 & 82.0 & Albumin & 120 & 60.0 \\
\hline Transfusion $>4$ units & 160 & 80.0 & Transfusion $>4$ units & 115 & 57.5 \\
\hline Hemiplegia & 147 & 73.5 & Impaired sensorium & 108 & 54.0 \\
\hline Dyspnea & 126 & 63.0 & DNR & 103 & 51.5 \\
\hline
\end{tabular}

$R B C$, Red blood cell; COPD, chronic obstructive pulmonary disease; $D N R$, do not resuscitate.

of its nationally based patient population and easily retrieved computerized patient data. The National VA Surgical Quality Improvement Program was established in 1991 as a model of a multi-institutional outcomes study. Patient risk and postoperative data on more than 300,000 operative encounters have been collected, 184,319 of which were for noncardiac procedures. ${ }^{13,15}$ Variable definitions and data collection were standardized across surgical subspecialties so that aggregate analyses would be possible.

The purpose of this project was to use these data to construct a model of preoperative patient risk for mortality and morbidity within 30 days of major pulmonary resections. Data collection was prospective and recent (1991-1995), eliminating any temporal bias that existed in previous single-institution reports that spanned decades and may not reflect current clinical practice. Because a dedicated surgical nurse reviewer acquired all of the data prospectively, its reproducibility and accuracy were assured. Interpretive test results, such as electrocardiography and spirometry, were not included in this study.

The 30-day mortality and morbidity rates $(5.2 \%$ and $24.1 \%$, respectively) from this multi-institution series are in the range of those published from single-institution retrospective series (mortality 3\%-14\%; morbidity 10\%-25\%). ${ }^{1-9}$ The largest pneumonectomy series $(\mathrm{n}=$ 244) from the Mayo Clinic reported $11 \%$ deaths and 


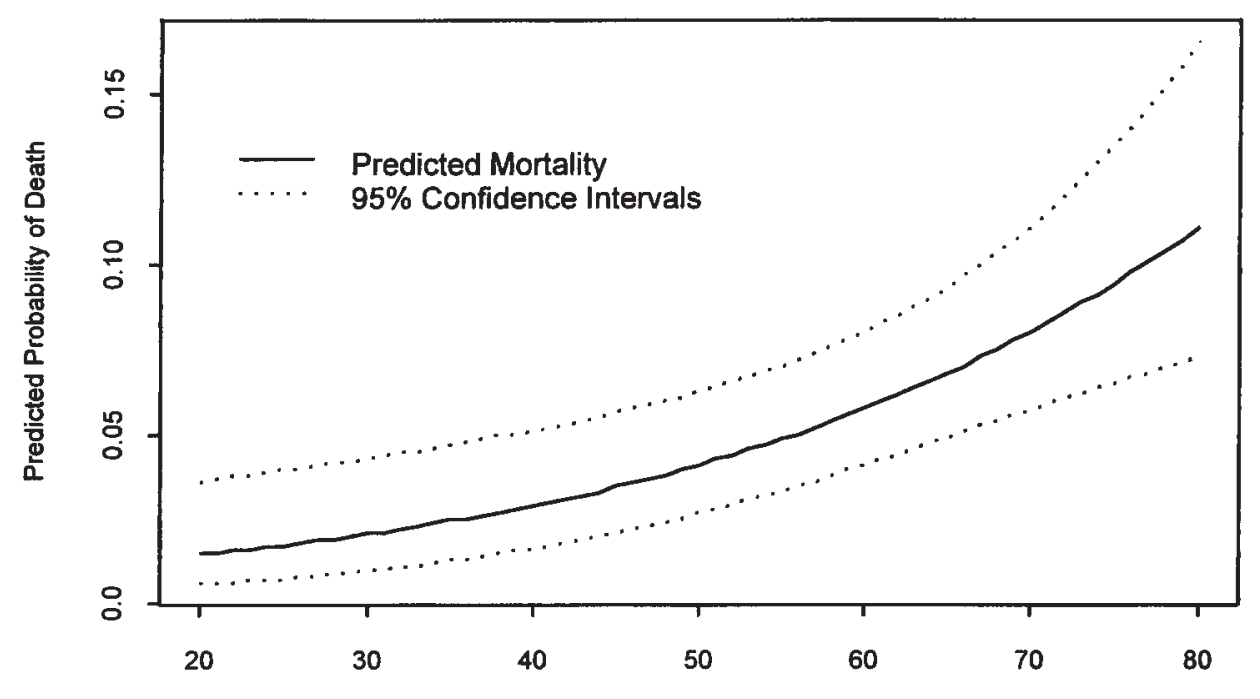

Age in years

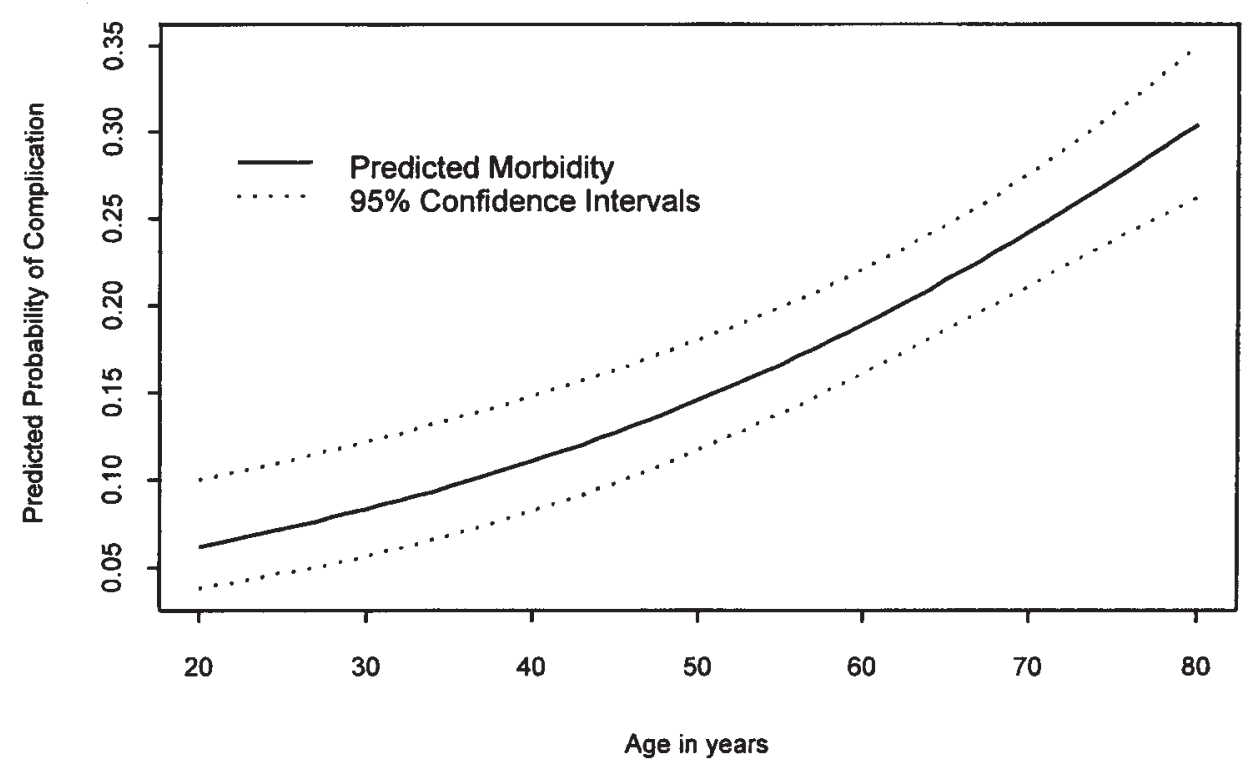

Fig 1. Statistical nomograms were constructed with $95 \%$ confidence intervals to demonstrate the results. Top, Probability of death for age in years. Bottom, Probability of a complication for patient by age. Note that risk increases with age.

$24 \%$ major morbidity within 30 days. These procedures were performed for cancer and infection. ${ }^{10}$ Deslauriers and associates ${ }^{11}$ reported a series of 1076 patients from several centers in Canada who had undergone elective lobectomy or pneumonectomy for cancer from 1978 until 1984. They observed an overall $3.2 \%$ mortality and a $19 \%$ morbidity rate, which are similar to our overall mortality and morbidity rates.

Multi-institution, prospective data are available from the Lung Cancer Study Group (1979-1981). Ginsberg and colleagues ${ }^{12}$ reported a $2.6 \%$ mortality for a lobectomy $(\mathrm{n}=1058)$ and a $6.2 \%$ mortality for a pneumonectomy $(n=569)$ for cancer. Silvestri and colleagues ${ }^{28}$ published data from hospital discharges in the state of South Carolina from 1991 until 1995. This study observed a 30 -day mortality of $11.8 \%$ for pneumonectomy and $3.0 \%$ for lobectomy performed by board-certified thoracic surgeons. Both of these series 

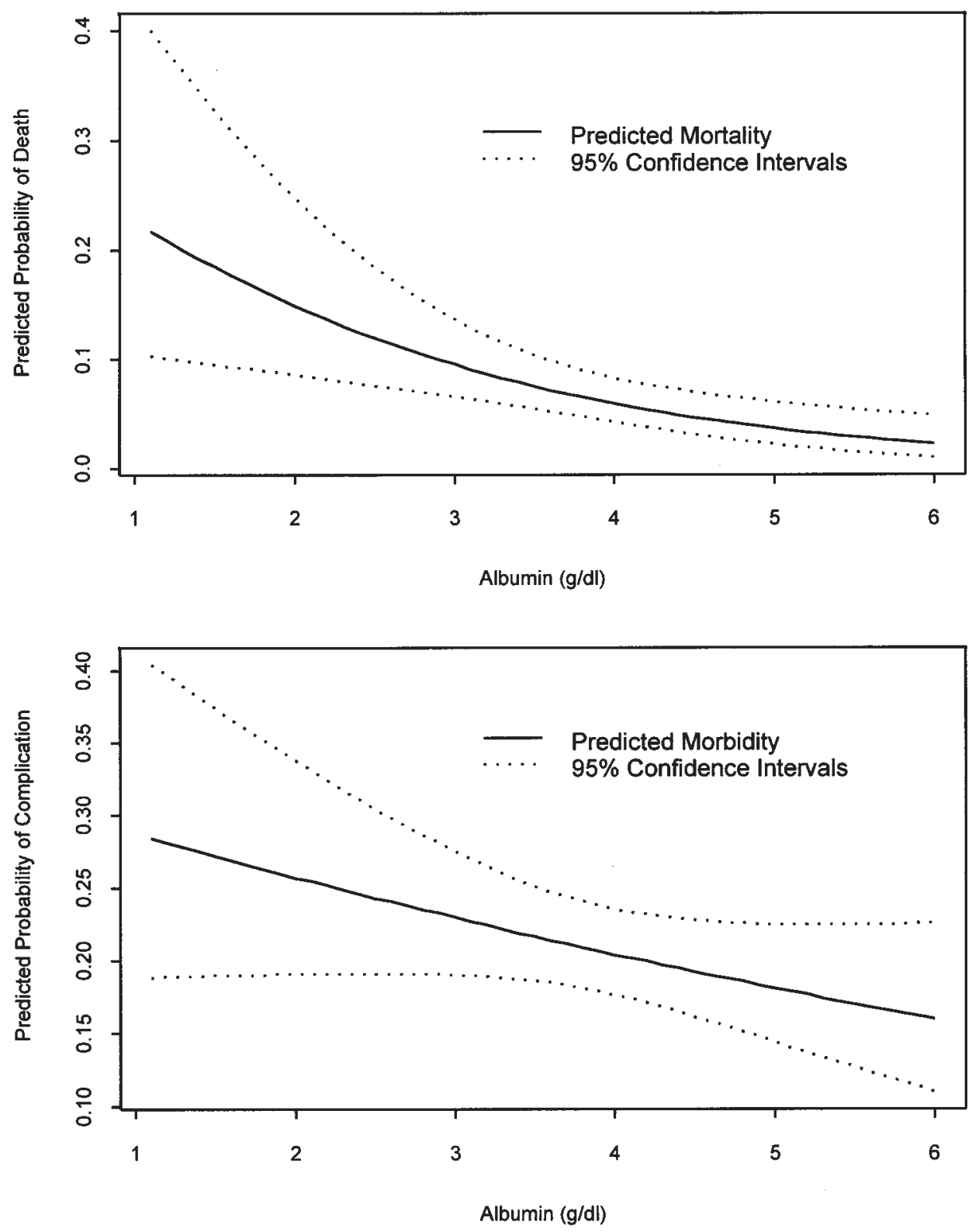

Fig 2. Statistical nomograms were constructed with $95 \%$ confidence intervals to demonstrate the results. Top, Probability of death for serum albumin. Bottom, Probability of a complication for patient by serum albumin. Note that risk decreases with improved nutritional status.

included elective operations performed for cancer. Our VA data included 3516 consecutive patients who underwent a lobectomy or pneumonectomy for any cause, elective or emergency. There were 19 emergency procedures for infection or massive hemoptysis, and 11 urgent or emergency procedures were performed on patients who had previously asked not to be resuscitated in the event of a cardiac arrest. Significant comor- bidity is common in this veteran population, including $39 \%$ of patients with chronic obstructive lung disease, $33 \%$ with moderate or severe dyspnea, $19 \%$ with chronic alcoholism, $11 \%$ with diabetes, and $10 \%$ with a history of a stroke or transient ischemic attack. These factors may explain the higher mortality rates observed in this population of male veterans. In fact, if the mortality models for lobectomy and pneumonectomy were 
used to a define a "low risk" subset of patients (expected mortality $\leq 5.0 \%$ ), observed mortality was actually $2.5 \%$ for lobectomy and $7.0 \%$ for pneumonectomy.

Limitations of study. The study population is predominantly male. The 1997 cancer statistics demonstrate that $40 \%$ of newly diagnosed cases of lung cancer occur in women. ${ }^{29}$ Clearly, the generalizability of this VA study will need to be verified in a more heterogeneous population. Early efforts by the Society of Thoracic Surgeons may accomplish this goal, and this VA study can act as a model for future analytical risk models. In an effort for data consistency and completeness, only easily quantifiable data were included and no subspecialty procedure-specific morbidity (ie, bronchopleural fistula instead of pneumonia) was collected, allowing consistent data collection throughout the VA system. Future studies are being designed to include procedure-specific variable collection, such as exercise oximetry, spirometry, and predicted postresection forced expiratory volume in 1 second.

Clinical relevance of models. Two separate analyses were undertaken after univariate analyses identified potential variables associated with mortality and morbidity. The first model consisted of preoperative variables that would be readily available to clinicians, as well as the type of resection planned (lobectomy or pneumonectomy). The mortality model demonstrated the significance of patient age, pulmonary reserve (dyspnea class), level of cognition, nutritional status (serum albumin), liver function (serum prothrombin time), clinical cancer stage, and need for a pneumonectomy on perioperative survival. If one added the intraoperative variables to this model, only the operative blood loss (a measure of the difficulty of the operation) added independent prognostic information.

The morbidity models included different variables. In addition to patient age, serum albumin, and dyspnea class, preoperative smoking, weight loss, and hemiplegia were significant predictors of a complicated postoperative course. Intraoperative variables that significantly predicted a complication included operative time and blood loss, both markers of a more difficult operation, whereas there was no difference in the risk of a complication between the two procedures once the model accounted for these other significant variables. Figs 1 and 2 demonstrate the results of two continuous variables (age in years and serum albumin level before operation) on mortality and morbidity.

\section{Conclusion}

This recent series of lobectomy and pneumonectomy in the Department of VA Medical Centers demonstrates the feasibility of a prospective, national, multicenter perioperative study. The outcome results obtained were consistent with those published in the literature. The large size of the population allowed the creation and validation of a risk-adjusted model for patient selection for major pulmonary resections. Therefore, in addition to the clinically relevant assessment of the patient's health, one can use the $\beta$ coefficients of the significant factors present in a specific patient to determine the probability of an adverse event in that patient. This is the largest data set of its type and therefore allowed construction of the most predictive model to date. Future prospective multicenter studies of patients undergoing major pulmonary resections may include other variables (ie, spirometry and exercise oximetry), thereby increasing the overall predictive validity of the models.

\section{REFERENCES}

1. Massie E, Valle AR. Cardiac arrhythmias complicating total pneumonectomy. Ann Intern Med 1947;26:231-9.

2. Bergh NP, Dottori O, Malmberg R. Prophylactic digitalis in thoracic surgery. Scand J Respir Dis 1967;48:197-200.

3. Stougard J. Cardiac arrhythmias following pneumonectomy. Thorax 1969;24:568-572.

4. Harmon H, Fergus S, Cole FH. Pneumonectomy: review of 351 cases. Ann Surg 1976;183:719-22.

5. Nagasaki F, Flehinger BJ, Martini N. Complications of surgery in the treatment of carcinoma of the lung. Chest 1982;82:25-29.

6. Keagy BA, Schorlemmer GR, Murray GF, Starek PJ, Wilcox BR. Correlation of preoperative pulmonary function testing with clinical course in patients after pneumonectomy. Ann Thorac Surg 1983;36:253-7.

7. Wahi R, McMurtrey MJ, DeCaro LF, et al. Determinants of perioperative morbidity and mortality after pneumonectomy. Ann Thorac Surg 1989;48:33-7.

8. Von Knorring J, Lepantalo M, Lindgren L, Lindfors O. Cardiac arrhythmias and myocardial ischemia after thoracotomy for lung cancer. Ann Thorac Surg 992;53:642-7.

9. Kearney DJ, Lee TH, Reilly JJ, DeCamp MM, Sugarbaker DJ. Assessment of operative risk in patients undergoing lung resection: importance of predicted pulmonary function. Chest 1994; 104:753-8.

10. Krowka MJ, Pairolero PC, Trastek VF, Payne WS, Bernatz PE. Cardiac dysrhythmia following pneumonectomy: clinical correlates and prognostic significance. Chest 1987;91:490-5.

11. Deslauriers J, Ginsberg RJ, Dubois P, Beaulieu M, Goldberg M, Piraux M. Current operative morbidity associated with elective surgical resection for lung cancer. Can J Surg 1989;32:335-9.

12. Ginsberg RJ, Hill LD, Eagan RT, et al. Modern thirty-day operative mortality for surgical resections in lung cancer. J Thorac Cardiovasc Surg 1983;86:654-8.

13. Khuri SF, Daley J, Henderson W, et al. The National Veterans Administration Surgical Risk Study: risk adjustment for the comparative assessment of the quality of surgical care. J Am Coll Surg 1995;180:519-31.

14. Khuri SF, Daley J, Henderson W, et al. The Department of Veterans Affairs' NSQIP: The first national, validated, outcome- 
based, risk-adjusted, and peer-controlled program for the measurement and enhancement of the quality of surgical care. Ann Surg. In press.

15. Khuri SF, Daley J, Henderson, et al. Risk adjustment of the postoperative mortality rate for the comparative assessment of the quality of surgical care: results of the national Veterans Affairs Surgical Risk Study. J Am Coll Surg 1997;185:315-27.

16. Grover FL, Hammermeister KE, Burchfiel C, et al. Initial report of the Veterans Administration preoperative assessment study for cardiac surgery. Ann Thorac Surg 1990;50:12-28.

17. Hammermeister KE, Burchfiel C, Johnson R, Grover FL, for the VA surgeons and cardiologists. Identification of patients at greatest risk for developing major complications at cardiac surgery. Circulation 1990;82(Suppl):IV380-9.

18. Grover FL, Johnson RR, Hammermeister KE, the VA cardiac surgeons. Factors predictive of operative mortality among coronary artery bypass subsets. Ann Thorac Surg 1993;56:1296-307.

19. Buck SF. A method of estimation of missing values in multivariable data suitable for use with an electronic computer. J R Stat Soc (Series B) 1960;22:302-7.

20. Roberts JS, Capalbo GM. A SAS macro for estimating missing values in multivariable data. Dallas [TX]: SAS Users Group International Twelfth Annual Conference Proceedings, February 8-11, 1987

21. Efron B, Tibshirani R. Bootstrap methods for standard errors, confidence intervals, and other measures of statistical accuracy. Stat Sci 1986;1:54-77.

22. Sauerbrei W, Schumaker M. A bootstrap resampling procedure for model building: applications to the Cox regression model. Stat Med 1992;1:2093-109.

23. Harrell FE Jr, Lee KL, Matchar DB, Reichert TA. Regression models for prognostic prediction: advantages, problems, and suggested solutions. Cancer Treat Rep 1985;69:1071-7.

24. Harrell FE Jr, Lee KL, Califf RM, Pryor DB, Rosati RA. Regression modelling strategies for improved prediction. Stat Med 1984;3:143-52.

25. Hosmer DW, Lemeshow S. Applied logistic regression. New York: John Wiley; 1989.

26. Breslow NE, Day NE. Statistical methods in cancer research, Volume II. The design and analysis of cohort studies. Lyon, France: International Agency for Research on Cancer, 1987.

27. Landis JR, Koch GG. Measurement of observer agreement for categorical data. Biometrics 1997;33:159-74.

28. Silvestri GA, Handy J, Lackland D, Corley E, Reed CE. Specialists achieve better outcomes than generalists for lung cancer surgery. Chest 1998;114:675-80.

29. Parker SL, Tong T, Bolden S, Wingo PA. Cancer statistics1997. CA Cancer J Clin 1997;47-5-27.

\section{Appendix 1}

\section{National Surgical Quality Improvement Program Program Worksheet}

\section{A. PREOPERATIVE INFORMATION}

\section{GENERAL}

a. Diabetes mellitus

1. No

2. Oral

3. Insulin b. Current smoker within 2 weeks before admission

1. Yes

2. No

c. Alcohol > 2 drinks/day within 2 weeks before admission

1. Yes

2. No

d. Drug addiction

1. Yes

2. No

e. Dyspnea

1. No

2. Minimal exertion

3. Rest

f. Do not resuscitate status - this admission

1. Yes

2. No

g. Functional status

1. Independent

2. Partially dependent

3. Total dependent

\section{PULMONARY}

a. Ventilator dependent $>48$ hours

1. Yes

2. No

b. History of severe chronic obstructive pulmonary disease 1. Yes

2. No

c. Current pneumonia

1. Yes

2. No

\section{HEPATOBILIARY}

a. Hepatomegaly

1. Yes

2. No

b. Ascites

1. Yes

2. No

c. Esophageal varices

1. Yes

2. No

d. Active hepatitis

1. Yes

2. No

4. CARDIAC

a. History of myocardial infarction within past 6 months

1. Yes

2. No

b. Previous percutaneous transluminal coronary angioplasty

1. Yes

2. No

c. Previous operation with cardiopulmonary bypass

1. Yes

2. No

d. History of angina within month before the operation 1. Yes 
2. No

e. Congestive heart failure within 1 month before the operation

1. Yes

2. No

f. Hypertension requiring medication

1. Yes

2. No

\section{RENAL}

a. Acute renal failure (change in creatinine >

$$
2.0 \mathrm{mg} / \mathrm{dL} \text { ) }
$$

1. Yes

2. No

b. Currently requiring dialysis

1. Yes

2. No

\section{VASCULAR}

a. History of revascularization/amputation for peripheral vascular disease

1. Yes

2. No

b. Rest pain/gangrene

1. Yes

2. No

c. Absent peripheral pulses

1. Yes

2. No

\section{CENTRAL NERVOUS SYSTEM}

a. Impaired sensorium

1. Yes

2. No

b. Severe head trauma

1. Yes

2. No

c. History of coma

1. Yes

2. No

d. Quadriplegia

1. Yes

2. No

e. Paraplegia

1. Yes

2. No

f. Hemiplegia

1. Yes

2. No

g. History of transient ischemic attacks

1. Yes

2. No

h. Cerebrovascular accident residual neurologic deficit

1. Yes

2. No

i. Cerebrovascular accident/no neurologic deficit

1. Yes

2. No

j. Neuromuscular degenerative disease

1. Yes
2. No

k. Tumor involving the central nervous system

1. Yes

2. No

\section{NUTRITIONAL/IMMUNE/OTHER}

a. Disseminated cancer (stage IV)

1. Yes

2. No

b. Open wound or infection

1. Yes

2. No

c. Chronic steroid use

1. Yes

2. No

d. $>10 \%$ loss of body weight within last 6 months

1. Yes

2. No

e. Bleeding disorders

1. Yes

2. No

f. Transfusion $>4$ red blood cell units this admission

1. Yes

2. No

g. Number of prior operations this admission

\section{B. OPERATIVE INFORMATION}

1. Surgical specialty: (code)

2. Principal operation: (CPT code)

3. Other procedures: (CPT code)

4. Concomitant procedures: (code)

5. Postgraduate-year primary surgeon

6. Emergency case
a. Yes

b. No

7. Wound classification

a. Clean

b. Clean/contaminated

c. Contaminated

d. Infected

8. Redo

a. Yes

b. No

9. American Society of Anesthesiology class

10. Principal anesthesia technique
a. General
b. Spinal
c. Epidural
d. Regular/local

11. Time operation began (24-hour clock)

12. Intraoperative blood loss $(\mathrm{mL})($ minimal $=100)$

13. Number of red blood cell units transfused

\section{OUTCOME INFORMATION}

1. Postoperative diagnosis (ICD-9-Code)

2. Length of postoperative hospital stay (days)

3 . Thirty-day postoperative status

4. Date of death 
5. Return to operating room within 30 days after index procedure
a. Yes

b. No

6. Number of returns related to index procedure

7. CPT code

8. CPT code

9. CPT code

10. Number of returns unrelated to index procedure

11. CPT code

12. CPT code

13. CPT code

\section{COMPLICATIONS (See Table II)}

\section{E. LABORATORY VALUES}

\section{Preoperative (nearest to operation date)}

\begin{tabular}{|c|c|}
\hline a. Sodium & Month_ Day_ Year \\
\hline b. Potassium & __ Month__ Day___ Yea \\
\hline . Glucose & Month___ Day___ Year \\
\hline d. $\mathrm{BUN}$ & Month___ Day___ Year___ \\
\hline e. Creatinine_ & _ Month___ Day___ Yea \\
\hline f. $\mathrm{CK}$ & Month___ Day___ Year___ \\
\hline g. CK-MB & _ Month___ Day___ Year_ \\
\hline h. Albumin & _ Month___Day____Year_ \\
\hline i. Total bilirubin_ & Month___ Day___ Year \\
\hline ALT & _ Day___ Year__ \\
\hline k. $\mathrm{AST}_{2}$ & Day___ Year_ \\
\hline 1. $\mathrm{AP}$ & Month_ \\
\hline m. WBC & Month_ \\
\hline n. Hct & Month__ \\
\hline o. Platelets & __ Month___ Day____ Year_ \\
\hline p. PTT_ & Month___ Day___ Year_ \\
\hline q. PT__ & Month ___Day___Year_ \\
\hline
\end{tabular}

2. Postoperative laboratory values (record highest and lowest levels)
a. Sodium Month Day____ Year
b. Sodium Month Day_ Year
c. Potassium Month Day Year_
d. Potassium Month Day____ Year
e. Glucose___ Month___ Day___ Year
f. Creatinine Month Day____ Year
g. $\mathrm{CK}$ Month Day___ Year
h. CK-MB_ Month Day___ Year
i. Albumin___ Month___ Day___ Year_
j. Total bilirubin___ Month__ Day__ Year_
k. WBC__ Month__ Day__ Year

1. Het__ Month__ Day___ Year

Where $B U N$ is blood urea nitrogen, $C K$ is creatine kinase, $A P$ is alkaline phosphatase, $A L T$ is alanine aminotransferase, $A S T$ is aspartate aminotransferase, $W B C$ is white blood cell count, Hct is hematocrit, PTT is partial thromboplastin time, and $P T$ is prothrombin time.

\section{Appendix 2}

List of variables used in mortality and/or morbidity modeling (univariate $P<=.2$ and prevalence $\geq=0.5 \%$ )

\begin{tabular}{|c|c|}
\hline \multicolumn{2}{|c|}{ Mortality and morbidity } \\
\hline DRUGAD & Drug addiction \\
\hline DYSP & $\begin{array}{l}\text { Dyspnea (no vs minimal exertion or at } \\
\text { rest) }\end{array}$ \\
\hline DNR & Do not resuscitate status \\
\hline FNSTATUS & Functional status \\
\hline HXCOPD & $\begin{array}{l}\text { History of severe chronic obstructive } \\
\text { pulmonary disease }\end{array}$ \\
\hline CPNEUMON & Current pneumonia \\
\hline $\mathrm{HXCHF}$ & $\begin{array}{l}\text { Congestive heart failure within } 1 \text { month } \\
\text { preceding surgery }\end{array}$ \\
\hline HXPVD & $\begin{array}{l}\text { History of revascularization/amputation } \\
\text { for peripheral vascular disease }\end{array}$ \\
\hline ABPULSE & Absent peripheral pulse \\
\hline IMPSENS & Impaired sensorium \\
\hline HEMI & Hemiplegia \\
\hline CVANEURO & $\begin{array}{l}\text { Cerebrovascular accident/residual } \\
\text { neurologic deficit }\end{array}$ \\
\hline WTLOSS & $\begin{array}{l}>10 \% \text { loss in body weight within last } \\
6 \text { months }\end{array}$ \\
\hline BLEEDDIS & Bleeding disorders \\
\hline TRANSFUS & $\begin{array}{l}\text { Transfusion }>4 \text { red blood cell units this } \\
\text { admission }\end{array}$ \\
\hline EMERGNCY & Emergency case \\
\hline ASACLAS & American Society of Anesthesiology class \\
\hline AGE & Age \\
\hline PRALBUM & Serum albumin \\
\hline PRSODM & Sodium \\
\hline PRBUN & Blood urea nitrogen \\
\hline PRALKPH & Alkaline phosphatase \\
\hline PRHCT & Hematocrit \\
\hline PRPTT & Partial thromboplastin time \\
\hline \multicolumn{2}{|l|}{ Mortality only } \\
\hline SEX & Gender \\
\hline ETOH & $\begin{array}{l}\text { Alcohol }>2 \text { drinks/day within } 2 \text { weeks } \\
\text { before admission }\end{array}$ \\
\hline DISCANCR & Disseminated cancer \\
\hline STEROID & Long-term steroid use \\
\hline NOPER & $\begin{array}{l}\text { Number of returns related to index } \\
\text { procedure }\end{array}$ \\
\hline XSCORE & Complexity score of operation \\
\hline PRPTAS & Potassium \\
\hline PRSGOT & Aspartate aminotransferase \\
\hline PRPT & Prothrombin time \\
\hline \multicolumn{2}{|l|}{ Morbidity only } \\
\hline DIABETES & Diabetes \\
\hline SMOKE & $\begin{array}{l}\text { Current smoker within } 2 \text { weeks of } \\
\text { admission }\end{array}$ \\
\hline HYPERMED & Hypertension requiring medication \\
\hline HXTIA & History of transient ischemic attack \\
\hline CVANO & $\begin{array}{l}\text { Cerebrovascular accident/no neurologic } \\
\text { deficit }\end{array}$ \\
\hline WNDCLASS & Wound classification \\
\hline PRWBC & White blood cell count \\
\hline PRPLAT & Platelet counts \\
\hline
\end{tabular}

